\title{
Dual X-ray Absorptiometry
}

National Cancer Institute

\section{Source}

National Cancer Institute. Dual X-ray Absorptiometry. NCI Thesaurus. Code C48789.

A technique for scanning bone and measuring bone mineral density (BMD). A DXA scanner produces $2 \mathrm{X}$-ray beams, each with different energy levels. One beam is high energy while the other is low energy. The amount of $\mathrm{x}$-rays that pass through the bone is measured for each beam. This will vary depending on the thickness of the bone. Based on the difference between the 2 beams, the bone density can be measured. 